Tests with materials for the preservation of fishing nets, by Dr. Atkins and Mr. F. J. Warren, showed that on cotton netting 'Cuprinol', or Dr. Olie's method with cutch and ammoniacal copper sulphate, worked well, the latter being the cheaper of the two, while on trawl twines 'Cuprinol' (British Columbia grade) was best. Work on the preservation of ropes is proceeding. This number of the Journal concludes with abstracts of memoirs recording work done at the Plymouth Laboratory and published elsewhere.

N. B. Fales

\section{ARTIFICIAL STIMULATION OF RAIN AT KONGWA}

$\mathrm{D}^{2}$ URING January-April 1952, cloud-seeding experiments for the artificial stimulation of rain were carried out at Kongwa, Tanganyika, in connexion with the growing of groundnuts and other crops there by the Overseas Food Corporation. The director of the East African Meteorological Department, Mr. D. A. Davies, has already described the methods used (see Nature, 169, 1001; 1952), and now the results of the experiments have been published in the Department's "Memoirs"* and they prove to be very surprising.

The full details of the methods need not be given in this article, but, briefly, the seeding agents were released in a three-day cycle: silver iodide was released on the first day at a height of 14,000-15,000 ft., and hygroscopic particles (sea salt) at about $5,000 \mathrm{ft}$. on the second day. On the third day there was no seeding. Balloons carried canisters containing the seeding agent, which was released by exploding a small gunpowder charge by a time-fuse after a time of flight to bring the balloons to the desired height. The balloons were released downwind at a distance measured each day to ensure scattering of the particles over the same point at the centre of the farm area. Silver iodide is effective only at temperatures below $-5^{\circ} \mathrm{C}$. and so had to be released at a much greater height than the hygroscopic particles which were released in the lower part of the cumulus clouds. Rainfall was measured by a network of gauges distributed over the roughly rectangular area, 22 miles by 7 miles in size, occupied by the farm area. The long side of the rectangle lay from east to west. The wind was easterly for nearly all the 114 days of the experiments. There is a ridge of high land $3 .$. tuning from north to south in the centre, and rainfali is normally appreciably greater there than in the eastern and western ends of the area.

The results ure presented in isohyetal maps showing rainfal] in all the days of each type of seeding and no seeding, with comparison with normal. There is no description of the rainfall of any individual day. The overall results are briefly as follows. (a) On days of seeding in both ways, the rainfall in the central area over which the particles were released was reduced from a total of $9 \mathrm{in}$. on days of no seeding to one of 3-4 in. for the days of each type of seeding ; seeding thus appears to have produced a great decrease of rainfall over the central area. (b) On days of releasing hygroscopic particles, the rainfall in an area 6-12 miles downwind was above that on days

* East African Meteorological Department. Memoirs, Vol. 2, No. 10 : Reports on Experiments at Kongwa on Artificial Control of Rainfall, January-April 1952. By D. A. Davies, D. Hepburn and H. Sansom. of no seeding by up to 6 in. ; rainfall over an area 5 miles upwind was also increased by $2-3$ in. (c) On days of releasing silver iodide particles, rainfall upwind from the point of release was increased by at some places more than 6 in. ; downwind there was a small decrease. (d) On some occasions, clouds in which hygroscopic particles had been released were seen to disperse rapidly.

The memoir explains the increase of rainfall 6-12 miles downwind on days of seeding with hygroscopic particles by the delay in formation of large drops. No reason for result $(c)$ is suggested in the memoir, and there is no mention of a reversal of wind with height to carry the silver iodide particles to the east and so stimulate precipitation there.

On thirteen days when particles should have been released, it was already raining and balloons were not released because the fuses would have been extinguished. These days have been counted in the statistics as though seeding actually took place. As the memoir says, this makes the rainfall deficit in the central area even more surprising.

\section{FORMATION OF GALL STONES : PHYSICAL PROPERTIES OF BILE SALTS}

\author{
By A. J. H. RAINS and N. CRAWFORD \\ Surgical Professorial Unit, Queen Elizabeth Hospital, \\ Birmingham
}

CTONE formation in the various secretory or excretory ducts of the human body is one of the problems being studied in this Surgical Unit. The gall stone is the particular type of stone selected for study, especially that which, as a rule, primarily arises in the gall bladder - the pure cholesterol and the mixed gall stone, as opposed to the pigment or metabolic stone which arises in the hepatic ducts.

Pure cholesterol stones, single or multiple, are uncommon, for usually bile pigments, among other compounds, are included in varying amounts, either diffusely or by way of lamination, so that mixed stones are the rule. Because pure cholesterol stones exist with varying amounts of pigment, it is likely that the latter is an inclusion and that the prime disturbance involves the cholesterol. This is the 'crystallization out' of cholesterol ; but the chemical reaction which starts this off, or the character of the nucleus around which the cholesterol stone forms, is unknown, even though Wilkie ${ }^{x}$ noted that granular calculi of calcium and cholesterin were formed in the infected bile of an experimental animal. Gall stones have not been produced, at least convincingly, by any other means.

Two important contributory factors (or pieces of circumstantial evidence) in the formation of these gall stones are hypercholesterolæmia and infection; but to these a third factor should be added, namely, the power of the gall bladder to concentrate bile.

Associated with cholesterol are the salts of the bile acids, in the solutions of which the sterol is dissolved, and it was therefore considered that any chemical study of the factors responsible for the formation of gall stone must commence with the exploration of the cholesterol-bile acid relationship, first with the physico-chemical properties of the salts of the bile acids. 